\title{
Nota sobre el tiempo en el Quijote: la acción de la primera parte de 1605 transcurre en 1588
}

\author{
Sergio Moreno Jiménez \\ Universitat de Girona \\ smorenojimenez89@gmail.com
}

Fecha de recepción: 24/06/2012, Fecha de publicación: 21/12/2012

\section{Resumen}

En esta nota se intenta demostrar que Cervantes trató de respetar un calendario no inventado (el del año 1588) en la fijación del eje temporal sobre el que transcurren los hechos ficticios del Quijote de 1605.

Palabras clave

Cervantes; Quijote; 1588; 1605; tiempo; Agostini; Riquer

\section{Abstract}

The action of the first part of Don Quixote takes place in 1588

This note attempts to prove that Cervantes tried to take into account a non-invented. calendar (the one corresponding to 1588) when establishing the temporal axis which determines the Don Quixote's fiction of 1605.

Key words

Cervantes; Don Quixote; 1588; 1605; time; Agostini; Riquer 
Tendrá razón, en parte, quien afirme que no es posible establecer de manera fiable una línea cronológica en la que ubicar la acción de la Primera parte del Quijote. Aun así, resultan interesantes ciertas referencias al calendario que Cervantes disemina en la obra, no sin escamotear, por otro lado, la especificación del año en que tuvieron lugar. En efecto: «acertó a ser viernes aquel día» (I, 2) ${ }^{1}$, y «entraron en la mitad del día, que acertó a ser domingo» (I, 52) son las dos únicas referencias concretas de toda la Primera parte (1605) al día de la semana, y no deja de sorprender el hecho de que cada una se sitúe a un extremo opuesto de la obra: viernes es el día en que Don Quijote sale de casa por primera vez, todavía sin su escudero; y domingo el día en que llega a su aldea, enjaulado - $\mathrm{O}$ encantado-, en compañía del cura, el barbero, y su fiel Sancho Panza; como tampoco deja de ser llamativa la ausencia de otras menciones, y que éstas correspondan al primer día de aventura y al último. Entre estas dos referencias, la única que encontramos explícita, y no al día de la semana, sino al del mes, es la de la libranza pollinesca, "Fecha en las entrañas de Sierra Morena, a veinte y dos de agosto deste presente año» (I, 25).

Por supuesto, hay otras, que servirían para, en el caso de que se pudiera esclarecer esa línea cronológica y situarla en un año determinado, corroborar el acierto o fracaso del intento. Por ejemplo, se nos dice que aquel viernes «era uno de los calurosos del mes de julio» (I, 2) ${ }^{2}$, o sabemos también que transcurren exactamente trece días desde la redacción de la libranza pollinesca hasta la llegada de Don Quijote al aldea — lo que daría como fecha de llegada el 3 de setiembre- . Otro dato que cabe remarcar es que desde la primera salida hasta el 22 de agosto transcurren exactamente veinticinco días, perfectamente rastreables a través de las innumerables referencias que encontramos a lo largo de toda la obra ${ }^{3}$, y que nos dan otra pista, por lo menos en apariencia, sobre la meticulosidad del autor al situar el eje cronológico de manera verosímil; por lo tanto, nos encontraríamos con que DQ sale por primera vez un 28 de julio.

Ahora bien, ¿de qué año? Las pocas referencias que encontramos son muy vagas: "no ha mucho tiempo» (I, 1), «echaba la culpa a la malignidad del tiempo" — se refiere al manuscrito perdido y encontrado de Cide Hamete- (I, 9). Sin embargo, hay al menos dos que podrían servir para esbozar alguna hipótesis: en primer lugar, ayudarían a establecer el año en que se sitúa la acción del Qui-

1. En la nota 80 del segundo capítulo, Rico: "Algunos críticos han creído que esta referencia cronológica —el día de abstinencia de carne- corresponde a una exacta fecha histórica», en Rico, (2001: 53, n. 80). 2. Rico anota aquí: "Primera referencia cronológica de las muchas que se encontrarán en el $\mathrm{Q}$. [un poco más abajo se dice que es viernes]. La primera parte del Q. empieza un viernes de julio y termina un domingo de septiembre», etc., vid. Rico (2001: 45, n. 6).

3. "de allí a dos días» (89), "estuvo quince días en casa» (91), "hicieron noche en el camino de Puerto Lápice» (98), etc. Cada nuevo eslabón de la cronología se puede ir siguiendo sin problema alguno en la Primera parte, cosa que no sucede así en la Segunda. 
jote las fechas de composición y publicación de los libros que se encuentran en la biblioteca del hidalgo; en segundo lugar, datos históricos como el manuscrito del historiador Cide Hamete y la figura del traductor moro que lo traduce para Cervantes, en contraste con la expulsión de los moriscos que ya ha tenido lugar en la Segunda parte; por último, y éste será precisamente nuestro punto de partida, el relato del cautivo, a partir de su famosa frase, «Éste hará veinte y dos años que salí de casa de mi padre».

En este punto, Rico comenta: «Este dato, junto con los acontecimientos históricos que se narran (la llegada del Duque de Alba a Flandes en 1567, [...]), sitúan la narración del cautivo entre 1588 y 1590, según se cuente». Creo, sin embargo, que es posible concretar más: a la altura en que nos encontramos, en este momento de la narración, es 27 de agosto - hace cinco días que DQ ha fechado la misiva a 22 de agosto- , por lo que «Este hará veinte y dos años» nos deja los meses de setiembre a diciembre. De lo contrario, la expresión hubiera sido "el año próximo hará», etc. Ahora bien, el cautivo, antes de sumarse a las tropas del Duque de Alba, relata: «Embarquéme en Alicante, llegué con próspero viaje a Génova, fui desde allí a Milán, donde me acomodé de armas y de algunas galas de soldado, de donde quise ir a asentar mi plaza al Piamonte; y estando ya de camino para Alejandría de Palla, tuve nuevas que el gran Duque de Alba pasaba a Flandes» (I, 39).

El error de cálculo habitual aquí ha consistido en sumar «veinte y dos años» a 1567, y establecer el año en que transcurre la Primera parte del Quijote en $1589^{5}$, dado que el soldado no cuenta desde que se incorporó a las tropas del duque $^{6}$, sino desde que salió de casa de su padre. Por lo tanto, en ningún caso la acción podrá desarrollarse más tarde de 1588 , porque el cautivo como mínimo hubo de salir, para llevar a cabo todo lo que narra — viaje a Génova, a Milán, al Piamonte...-, a finales de 1566; de lo contrario, las tropas del Duque de Alba ya habrían partido hacia Flandes.

A lo sumo, se podría decir que salió a principios de 1567, pero entonces nos encontramos con el problema de explicar por qué afirma el cautivo que «este

4. Rico, Quijote (2001: 452, n. 17)

5. vid. Agostini (1958): «Este año hará veinte $y$ dos que sali de la casa de mi padre» —afirma el cautivo. Y refiere que, tras una breve estancia en Génova y en Milán, y ya en camino de Alejandría (del Piamonte), retrocedió para incorporarse a las tropas del Duque de Alba, que pasaba a Flandes. Dando valor aritmético a estas afirmaciones (cuya falsedad no tendría objeto alguno), resulta que, como el Duque de Alba pasó a Flandes en Septiembre de 1567 [*vemos que los datos que manejaba el maestro no eran totalmente correctos, pues el Duque llega, no parte, a Flandes a finales de agosto-principios de setiembre], los hechos contenidos en la Primera parte del Quijote ocurren veintidós años después, es decir, en 1589. Es posible que Cervantes no pensara en ello; pero, si hay que fijar la cronología del Quijote, es pie forzado admitir el año 1589 como fecha de partida». Y otros: MARtín de Riquer (2003); Ayala, F. (1974: 67).

6. El ejército se puso en marcha el 2 de junio de 1567 y llegó a Bruselas el 22 de agosto del mismo año. 
[año] hará» veintidós. Tanto más cuanto que no podemos alegar una sustracción de la línea cronológica para el relato intercalado, porque el mismo cautivo hará dos referencias explícitas, o se encontrará presente cuando otros las hagan, a las fechas en que se encuentra situada la acción: «a causa de tener noticias que de allí a un mes partía la flota de Sevilla a la Nueva España» [I, 42, p. 499], que coincidiría con finales de agosto, y es perfectamente plausible si tenemos en cuenta que la flota con destino a Veracruz zarpaba sólo una vez al año, en otoño; y «que para el día de San Miguel que vendrá...» [I, 42, p. 499], que cae en 29 de setiembre; ambos datos situarían la acción a finales de agosto.

Y aquí cabe recordar la razón por la que hemos tomado la decisión de analizar únicamente la estructura temporal de la Primera parte. En efecto, Sancho fechará la carta dirigida a su mujer [cuando ya sea gobernador, en el capítulo XXXVI de la Segunda parte] el día "veinte de julio de 1614»" lo que supondría todo un trastoque de cualquier posible cronología establecida en la Primera parte. Ni que decir tiene que Cervantes no escribió la Primera parte pensando en hacer transcurrir la acción en un futuro cercano ${ }^{8}$, y que la única motivación que tuvo para establecer esta fecha de manera tan explícita - recordemos que, en toda la Primera parte, no hay una sola referencia al ańo en que transcurre la narración- fue la publicación, en 1614, de un Segundo tomo del ingenioso hidalgo Don Quijote de la Mancha, y "compuesto por el licenciado Alonso Fernández de Avellaneda, natural de la villa de Tordesillas». De este modo, Cervantes quiso ridiculizar o inutilizar la obra apócrifa por inverosímil, desde su propia Segunda parte, y vengarse así, además, de las calumnias que le lanza Avellaneda en el prólogo y, sobre todo, en el capítulo IV. El problema es que, tal vez sin darle importancia, tal vez a pesar de todo, tal vez por descuido, también refutó la estructura temporal de su Primera parte. Pero, repetimos, no tiene sentido alguno a nuestro juicio intentar establecer un eje temporal consecuente entre ambas partes.

No sabemos realmente si Cervantes dio tanta importancia a la concepción de un eje espacio-tiempo, no sólo verosímil —que ya lo es—, sino perfectamente adecuado con la realidad. Estas notas pretenden demostrar que sí, al menos en lo que a la Primera parte se refiere, y las razones por las que ello no fue posible, o no hubo interés, en la redacción de la Segunda, y de ahí la importancia de separar ambas partes para su análisis.

Por lo tanto, de todo lo dicho extraemos: que la acción de la Primera parte dura exactamente 38 días, perfectamente rastreables, como decimos, dada la meticulosidad de Cervantes a la hora de explicitar el tiempo transcurrido; que desde la primera salida hasta la fecha de la libranza pollinesca - 22 de agostotranscurren 25 días, y otros 13 desde ese día hasta el domingo de setiembre en

7. Rico (2001: 932).

8. "no ha mucho tiempo que vivía..." ( I, 1). 
que la comitiva llega de regreso al aldea; que, por lo tanto, Don Quijote sale solo un 28 de julio, y llega enjaulado en compañía de Sancho, el cura y el barbero un 3 de setiembre.

Si introducimos estos datos en un calendario de $1588^{\circ}$, nos encontraremos con que Don Quijote sale por primera vez solo un Viernes, 28 de julio de 1588; pasa veinticinco días entre la primera salida, la convalecencia en casa, y la segunda salida, con Sancho, hasta la llegada a Sierra Morena, donde fecha la misiva a 22 de agosto; y, finalmente, engañado por Micomicona, el cura y el barbero, regresa a su aldea trece días después, un Domingo, 3 de setiembre de 1588, como se desgrana en esta relación:

- Viernes, 28 de julio de 1588: Primera salida de D.Q.

- Sábado, 29 de julio de 1588: D.Q. regresa a la aldea, molido y armado caballero.

- Domingo, 30 de julio de 1588: Escrutinio del cura y el barbero. Quema de libros durante la noche.

- Martes, 1 de agosto de 1588: D.Q. despierta de su molimiento.

- Miércoles, 16 de agosto de 1588: Segunda salida, de noche y ya con Sancho.

- Jueves, 17 de agosto de 1588: D.Q. y Sancho han caminado toda la noche. «Los molinos de viento», llegan al anochecer al camino de Puerto Lápice.

- Viernes, 18 de agosto de 1588: Puerto Lápice. «Aventura del vizcaíno».

- Sábado, 19 de agosto de 1588: Historia de «Marcela y Grisóstomo».

- Domingo, 20 de agosto de 1588: «Entierro de Grisóstomo». «Episodio de los yangüeses». Llegada a una nueva venta. «Maritornes, el arriero y el ventero».

- Lunes, 21 de agosto de 1588: Manteamiento de Sancho. "La batalla de los rebaños». La Santa Compaña.

- Martes, 22 de agosto de 1588: Aventura de los batanes, entre la madrugada avanzada y el alba. "El yelmo de Mambrino». «El buen caballero andante». «Aventura de los galeotes». Hallazgo de la maleta y el cartapacio. Historia de Cardenio. Locura de D.Q., que imita a Amadís. D.Q. escribe la carta, fechada el 22 de agosto de 1588. Han transcurrido 25 días [se puede comprobar] desde la Primera salida de D.Q., un día «de los calurosos del mes de julio», que "acertó a ser viernes».

- Sábado 26 de agosto de 1588: D.Q. ha estado haciendo penitencia mientras Sancho iba a la venta [cuando debería haber ido a entregar la misiva a Dulcinea]. Sancho regresa. Historia de Cardenio [continuación]. Historia de Dorotea. Historia de la princesa Micomicona. Camino al reino de Micomicón.

- Domingo, 27 de agosto de 1588: Llegada a la venta de toda la comitiva. «El curioso impertinente». «Las armas y las letras». «Historia del cautivo»:

- Lunes, 28 de agosto de 1588: Donna Clara y Don Luís. «D.Q. atado». Pleito de la albarda y el yelmo. Los cuadrilleros.

- Martes, 29 de agosto de 1588: Porque "dos días eran ya pasados los que había

9. Calendario que, vale decir, no tenían a mano F. Ayala (1974), Agostini (1958) o Martín de Riquer (2003) cuando analizaron el funcionamiento del tiempo en el Quijote. Este calendario se ha extraído del enorme trabajo de A. Cappelli (1969: 87-88), para comprobar la coincidencia: Viernes 28 de Julio de 1588, Domingo 3 de setiembre de 1588; los años de coincidencia (1969: 87). 
que toda aquella ilustre compañía estaba en la venta». Don Quijote enjaulado. Disputa sobre los libros de caballerías. El lago hirviente. El soldado fanfarrón.

- Domingo, 3 de setiembre de 1588: Porque "y al cabo de seis días llegaron a la aldea». La comitiva llega a la aldea. Fin de la primera parte.

Si el lector quiere consultar el calendario especificado en la última nota a pie de página, comprobará que las dos únicas referencias al día de la semana coinciden sólo si introducimos el eje temporal en 1588, ya que, de hacerlo en 1589, DQ no hubiera salido un Viernes, sino un Sábado.

Creemos oportuno señalar, para concluir estas breves notas, que las mismas no contradicen el trabajo de $\mathrm{Stagg}^{10}$ en lo que se refiere a la ordenación original de los episodios y su reordenación final. En efecto, la historia de Marcela y Grisóstomo y el entierro del segundo — que como muy acertadamente señaló el mismo crítico posiblemente se ubicaban después de la llegada a Sierra Morena y justo antes del capítulo XXV, hasta que Cervantes decidió que confluían demasiados relatos intercalados y trasladó ese interludio pastoril a los capítulos XI$\mathrm{XV}$ - se sitúa en una zona escarpada, montañesa, que contrasta con la llanura castellana que se nos venía describiendo en el capítulo anterior, el del vizcaíno. Además, no olvidemos que tras la aventura de los yangüeses (situada justo a continuación de la de Marcela y Grisóstomo), Sancho recuerda la del vizcaíno como si acabara de suceder inmediatamente antes de ésta.

Y afirmamos que estas tesis no afectan a nuestro marco temporal, dado que, tanto si situamos la acción de Marcela y Grisóstomo en Sierra Morena, como si lo hacemos en el lugar que finalmente Cervantes les confirió, dicha acción sigue ocupando dos días de acción narrativa, lo que no afecta en absoluto al marco temporal, sobre todo si tenemos en cuenta que siempre se situó (en cualquiera de los dos casos lo hizo) entre la primera salida de DQ y la datación de la libranza pollinesca, y por lo tanto las fechas dadas seguirían coincidiendo.

10. Véase StagG, (1959: 2-12). 


\section{Bibliografía}

Agostini, E. R., Breve estudio del tiempo y del espacio en el 'Quijote', Discurso de ingreso en el Instituto de Estudios Manchegos, 23 abril 1958.

Ayala, F., Cervantes y Quevedo, Barcelona, Seix Barral

Cervantes, M. de, Don Quijote de la Mancha, ed. Francisco Rico, Barcelona, Crítica, 2001.

Capelli, A., Cronologia, cronografia e calendario perpetuo: Dal principio dell'èra cristiana ai nostri giorni, Milán, U. Hoepli, 1969.

RiQuer, M. de "La acción del Quijote transcurre en el verano de 1614", en Para leer a Cervantes, Barcelona, El acantilado, 2003, 305-316.

Segre, C. Las estructuras y el tiempo en el Quijote, Barcelona, Planeta, 1976.

STAGG, G., "Revision in Don Quijtote Part I", Hispanic studies in Honour of I. González Llubera, Oxford, 1959, 347-366. 